\title{
Increasing ABB FlexPicker Robot's Degree of Freedom (DOF) using Flexible End Effector
}

\author{
M. H. Nordin ${ }^{1, *}, K$. Selvaraju ${ }^{1,}$, and M. Fathullah ${ }^{2,3}$ \\ ${ }^{1}$ Department of Robotics and Automation, Faculty of Manufacturing Engineering, Universiti Teknikal \\ Malaysia Melaka (UTeM), Hang Tuah Jaya, 76100 Durian Tunggal, Melaka, Malaysia \\ ${ }^{2}$ Center of Excellence Geopolymer and Green Technology (CEGeoGTech), Universiti Malaysia Perlis \\ (UniMAP), 01000 Kangar, Perlis, Malaysia. \\ ${ }^{3}$ School of Manufacturing Engineering, Universiti Malaysia Perlis (UniMAP), Pauh Putra Campus, \\ 02600 Arau, Perlis, Malaysia
}

\begin{abstract}
The commissioning of a high speed parallel robot such as the $\mathrm{ABB}$ Flexpicker Robot into the industrial environment provides greater flexibility in picking, packaging or palletizing tasks. However, current configuration of this robot only allows up to four-degree-of-freedom (DOF) which restricted its function to perform simple or complex automated assembly task. Therefore, the possibility of increasing one additional degree-of-freedom for the parallel robot was investigated. By attaching a flexible vacuum hose to the robot's end effector, it can be controlled by using a servomotor that can manipulate its angle of suction up to 90 degrees. With this new configuration, one DOF has been introduced for this robot. Several tests had been conducted to evaluate the flexibility and performance of the end effector which includes varying loads and angles. From the analysis, it is found that the end-effector can lift weights up to $1 \mathrm{~kg}$ due to sufficient vacuum pressure; however, it could perform bending up to 90 degrees for maximum load of 600 grams only.
\end{abstract}

\section{Introduction}

Parallel robots are a relatively young type robot that has been developed over 25 years ago and has been implemented in productions for about 15 years. Parallel robots are robots with closed-loop mechanism and consist of three or more rotary or prismatic axes that functional parallel to each other. Parallel robots are designed for high-speed applications, manufacturing, packaging, material handling and assembly purpose. A majority of the highspeed robot is based on delta design which has been developed in 1988 by the Ecole Polytechnique Fédérale de Lausanne (EPFL). Delta architecture robots are highly dynamics due to its lightweight and parallel design. The first commercial Delta robots were produced

\footnotetext{
*Corresponding author: hisham@utem.edu.my
} 
by BOSCH and ASEA Brown Boveri, (ABB) companies. However, ABB FlexPicker is the most sold and fastest commercial parallel robot in the world today [1][2].

Delta robot - FlexPicker IRB 340 (as shown in Figure 1) by ABB that was installed in Robotic Lab, Faculty of Manufacturing Engineering, UTeM, is one of the top most leading robot for industrial use for picking up lightweight products. This robot consists of 4 degree of freedom (DOF); Scara motions which are well adapted to pick and place tasks. All the arms were linked in parallel with three DOF of translation to carry an object from one point to another and a theta axis that enables rotation about a given axis in world coordinates.

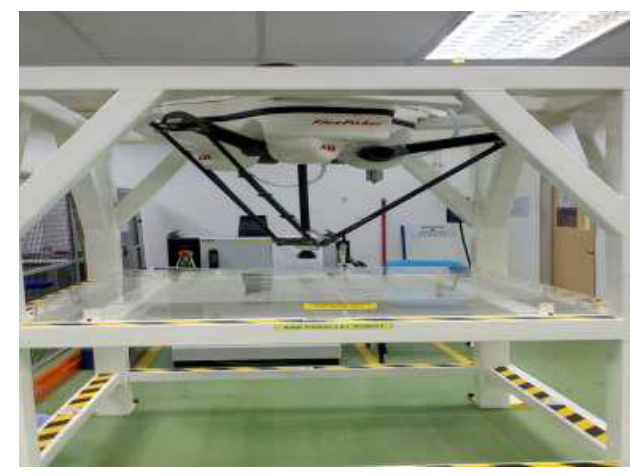

Fig. 1. ABB Delta robot - FlexPicker IRB 340 (Robotic Lab, FKP).

The aim of this project is to go one step further and to show that is indeed possible to increase the degree of freedom of the ABB FlexPicker robot by at least one degree of freedom for automated product assembly task. An end effector has been designed to increase the degree of freedom of the robot. The current robot in investigation uses Vacuum gripper (shown in Figure 2) with a fixed end effector. It consists of four DOF whereby three translations in $\mathrm{x}, \mathrm{y}, \mathrm{z}$ and one rotation about a given axis. The vacuum gripper which was attached to the fixed end-effector provides minimal flexibility of movement. For example, it only picks and place an object in a vertical direction and does not provide gripping at any angles.

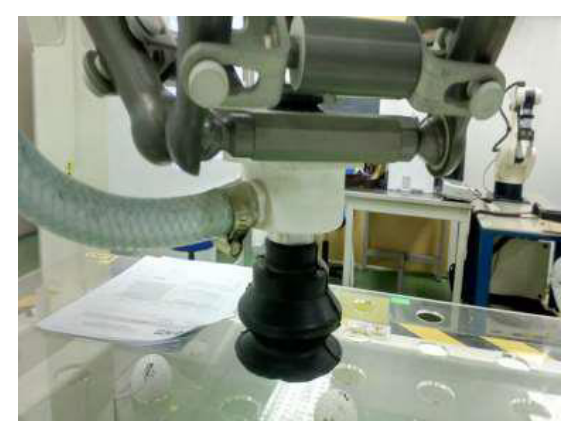

Fig. 2. End-effector and vacuum gripper.

End-effector is one of the most important factors for increasing flexibility and degree of freedom of a robot. There are many types of end-effector being used in current industries for ABB FlexPicker such as mono pick, multi-suction cup, magnetic grippers and parallel grippers [3]. However, all of this end-effector can only be moved in rotational motion as 
additional to the $\mathrm{x}, \mathrm{y}$, and $\mathrm{z}$-motions. Therefore, an initiative to design a flexible endeffector was taken to solve this problem so that the robot can perform gripping at vertical direction with a specified angle. This flexible end-effector is believed to increase the robot's degree of freedom by at least one degree, thus could increase the flexibility and improving the productivity.

\section{Design overview}

Figure 3 shows the selected design of the end-effector that has been fabricated and investigated in this project. Table 1 indicates the name of the parts in this design. This design is basically powered by a servo motor. In general servo motor is a rotary type motor that can be coded to output a signal that allows the shaft of the motor to revolve to a specified angular position. Therefore, when the servo motor rotates, it pulls the joint and eventually forces the flexible tube towards the direction of the servo motor. The top ring holder is used to hold the middle part of the flexible tube in stationery, thus the upper part is able to stretch and bend to the desired angle. In this case, the bending angle of the tube can be controlled by manipulating the angular rotation of the servo motor.

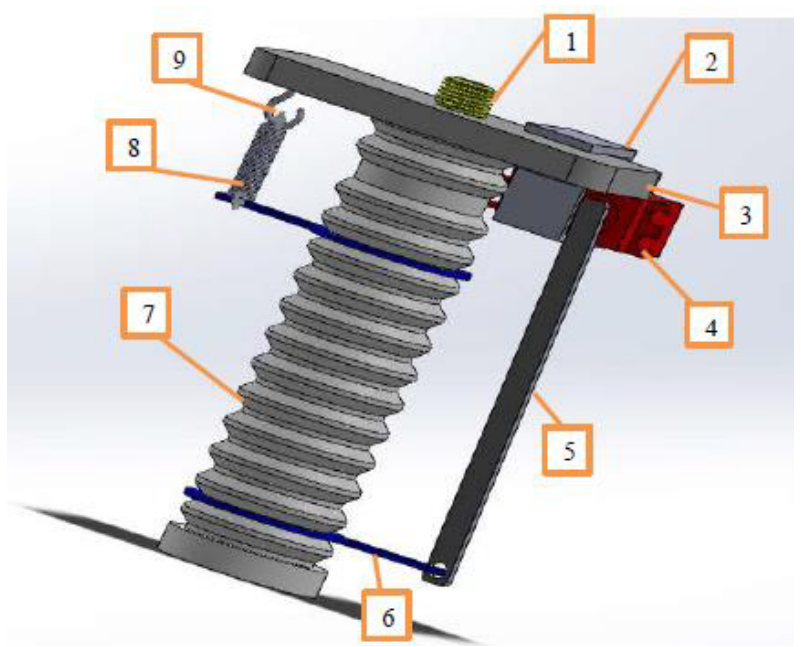

Fig. 3. Final design of end-effector.

Table 1. List of parts.

\begin{tabular}{|c|l|}
\hline No & \multicolumn{1}{|c|}{ Name of Parts } \\
\hline 1 & Hollow screw \\
\hline 2 & Base \\
\hline 3 & Servo motor \\
\hline 4 & Joint \\
\hline 5 & Ring connector \\
\hline 6 & Flexible hollow tube \\
\hline 7 & Rigid holder \\
\hline
\end{tabular}


Among the advantages of using this design as an effector for the ABB Flexpicker are because of its durability, incur minimal noise, simple design yet flexible and easier to bent by using the servo motor. However, the servo motor is not as fast as a pneumatic cylinder, nevertheless, due to its lightweight property, the servo motor is more desirable to be attached to the ABB robot as to decrease additional payload.

\section{Experiment details}

The prototype of the end-effector was attached to the ABB FlexPicker by screwing it firmly to the robot, replacing the original suction cup as shown in Figure 4. A pre-programmed microcontroller (Arduino) was used in this experiment to control the angle of the servo motor, initially from $0^{\circ}$ to $90^{\circ}$. By controlling the angle of the servo motor, the angle of the hose can be found by measuring the angle between both ends of the hose as illustrated in Figure 5. Initially, the attached end-effector was tested without any bending to determine the maximum load it can withstand. The suction force provided by the robot is constant at $0.4 \mathrm{MPa}$. Next, without any load, the servo motor was operated for different specified angle to investigate the flexibility of the end effector and the resulting angle of bending for the vacuum hose. The resulting hose bending angles were then recorded.

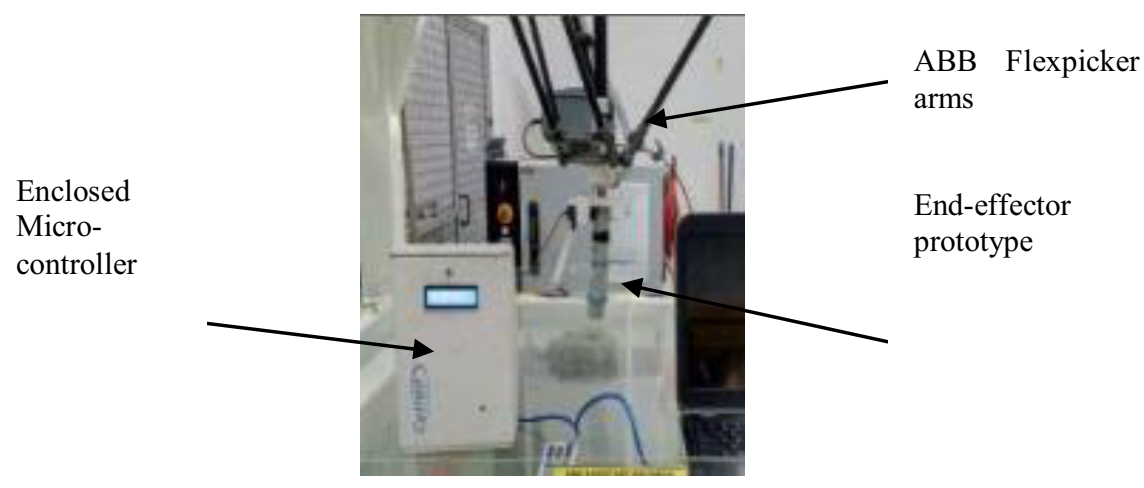

Fig. 4. End-effector attached to the ABB Flexpicker robot arms.

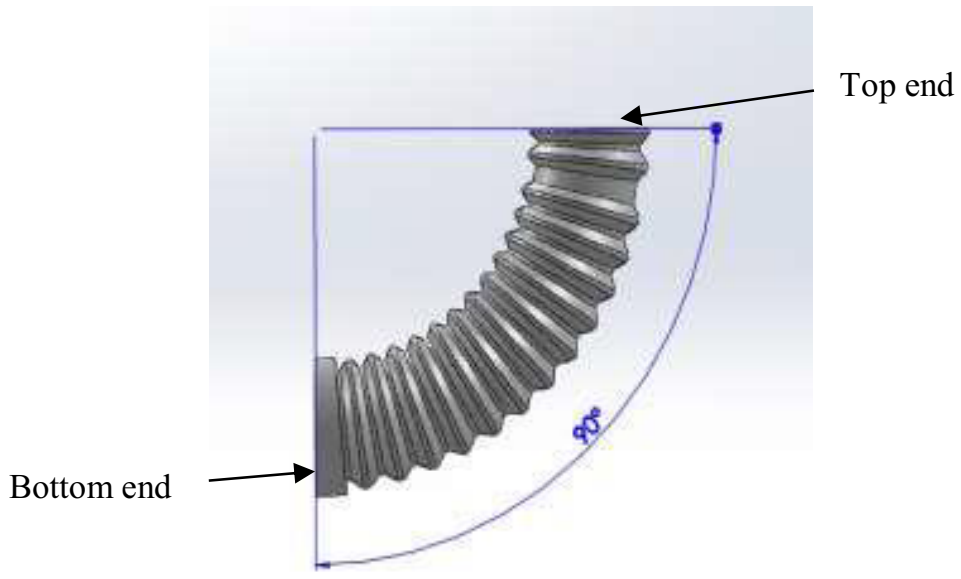

Fig. 5. Measuring hose bending angle. 
The experiment was then repeated again but with varying loads attached to the end of the suction hose. Based on the maximum allowable load that was determined from the previous experiment, the load was varied gradually with $100 \mathrm{~g}$ increment. The result was then recorded and analyzed for the bending motion.

\section{Results and discussion}

The first test to determine the maximum load the end-effector can withstand resulting in failure where the suction force from the robotic system had crushed the vacuum hose inwards, regardless of the load weight. To strengthen the hose, metal rings were inserted at every crevice of the hose and the test was resumed. It was found out that the maximum load it can hold are approximately $1 \mathrm{~kg}$.

According to the obtained result, the lifting force induced by the ABB FlexPicker is sufficient to hold the maximum weight of $1 \mathrm{~kg}$. The results show the load can still be gripped by the supplied vacuum pressure. To proof this, a simple calculation was done by calculating the holding force required by a maximum load of $1 \mathrm{~kg}$ and the maximum lifting force offered by the system at $0.4 \mathrm{MPa}$ vacuum pressure.

The actual holding force required to carry $1 \mathrm{~kg}$ of the load by the flexible end-effector can be calculated by using the following equation [4]:

$$
\mathrm{F}_{\mathrm{H}}=\mathrm{mx}(\mathrm{g}+\mathrm{a}) \times \mathrm{s}
$$

Where:

$$
\begin{aligned}
\mathrm{F}_{\mathrm{H}} & =\text { Holding force }(\mathrm{N}) \\
\mathrm{m} & =\text { Mass }(\mathrm{kg}) \\
\mathrm{g} & =\text { Acceleration due to gravity }\left(9.81 \mathrm{~m} / \mathrm{s}^{2}\right) \\
\mathrm{a} & =\text { Acceleration of the system }\left(\mathrm{m} / \mathrm{s}^{2}\right) \\
\mathrm{s} & =\text { Safety factor }(1.5 \text { for linear and } 2 \text { for rotary movement })
\end{aligned}
$$

Maximum acceleration values of ABB FlexPicker robot is $100 \mathrm{~m} / \mathrm{s}^{2}$ [5]. Thus, for lifting 1 $\mathrm{kg}$ of load,

$$
\begin{aligned}
\mathrm{F}_{\mathrm{H}} & =1 \mathrm{~kg} \times\left(9.81 \mathrm{~m} / \mathrm{s}^{2}+100 \mathrm{~m} / \mathrm{s}^{2}\right) \times 2 \\
& =219.62 \mathrm{~N}
\end{aligned}
$$

Maximum suction force offered by the system;

$$
\mathrm{F}_{\mathrm{S}}=\mathrm{P} \times \mathrm{A}
$$

Where:

$$
\begin{aligned}
\mathrm{F}_{\mathrm{S}} & =\text { Suction force }(\mathrm{N}) \\
\mathrm{P} & =\text { Vacuum pressure }(\mathrm{Pa}) \\
\mathrm{A} & =\text { Size of suction cup }\left(\mathrm{m}^{2}\right)
\end{aligned}
$$

The area of flexible hollow tube;

$$
\mathrm{A}=\pi \mathrm{r}^{2}
$$




$$
\begin{aligned}
& =3.142 \times 0.03^{2} \\
& =0.00283 \mathrm{~m}^{2}
\end{aligned}
$$

Thus, the suction force;

$$
\begin{aligned}
\mathrm{F}_{\mathrm{S}} & =0.4 \mathrm{MPa} \times 0.00283 \mathrm{~m}^{2} \\
& =1130.9 \mathrm{~N}
\end{aligned}
$$

Comparing both the actual holding force $\left(\mathrm{F}_{\mathrm{H}}\right)$ and suction force $\left(\mathrm{F}_{\mathrm{S}}\right)$;

$$
\begin{aligned}
1130.9 \mathrm{~N} & >219.62 \mathrm{~N} \\
\mathrm{~F}_{\mathrm{S}} & >\mathrm{F}_{\mathrm{H}}
\end{aligned}
$$

From the calculation, it is proven that the result obtained from the weight lifting test on the gripping force exerted by the ABB FlexPicker is sufficient to hold the maximum weight of $1 \mathrm{~kg}$. However, in the case where the holding force is perpendicular to the gravitational force, the equation are given as below [4]:

$$
\mathrm{F}_{\mathrm{H}}=(\mathrm{m} / \mu) \times(\mathrm{g}+\mathrm{a}) \times \mathrm{s}
$$

Where:

$$
\begin{aligned}
\mathrm{F}_{\mathrm{H}} & =\text { Holding force }(\mathrm{N}) \\
\mathrm{m} & =\text { Mass }(\mathrm{kg}) \\
\mu & =\text { Frictional coefficient } \\
\mathrm{g} & =\text { Acceleration due to gravity }\left(9.81 \mathrm{~m} / \mathrm{s}^{2}\right) \\
\mathrm{a} & =\text { Acceleration of the system }\left(\mathrm{m} / \mathrm{s}^{2}\right) \\
\mathrm{s} & =\text { Safety factor }(1.5 \text { for linear and } 2 \text { for rotary movement })
\end{aligned}
$$

Empirical frictional value varies with different surface are shown below:

- Oily: 0.1

- Wet: $0.2-0.3$

- Wood, metal, glass, stone: 0.5

- Rough: 0.6

Assuming frictional coefficient, $\mu$ to be 0.5 , thus;

$$
\begin{aligned}
\mathrm{F}_{\mathrm{H}} & =(1 \mathrm{~kg} / 0.5) \times\left(9.81 \mathrm{~m} / \mathrm{s}^{2}+100 \mathrm{~m} / \mathrm{s}^{2}\right) \times 2 \\
& =439.24 \mathrm{~N}
\end{aligned}
$$

Therefore, it can be deduced that extra holding force is required for the case of perpendicular lifting for the current system. However, since the suction force provided by the system is higher, the $1 \mathrm{~kg}$ object can still be handled effectively by the end-effector.

For the bending test, the angle of bending achieved by the flexible end effector for a maximum of 90 degrees motor rotational angle is tabulated in Table 2. Without applying any load, as the angle of servo motor rotation increases, the actual bending of the vacuum hose decreases near to $8 \%$ towards desired angle of 90 degrees. The reason for this 
difference is due to the extra force required to overcome the stiffness of the vacuum hose which increases upon increasing angle of bending.

The angle of bending was then recorded for all loads and from the result, it is found that the maximum load that the servo motor can support is 600 gram and beyond that, the servo motor starts to jerk at a certain angle. For example, for 100 gram load, the average angle of bending achieved for servo motor at 90 degrees angle of rotation is just 79.3 degrees. The angle of bending decreases when the load increases due to the weight effect of the gravitational force. To achieve 90 degrees of hose bending for 100 gram to 600 gram load, the motor angle of rotation should be increased more than 90 degrees.

Table 2. Resulting vacuum hose angles.

\begin{tabular}{|c|c|c|c|c|c|c|c|c|c|c|c|}
\hline \multirow{2}{*}{$\begin{array}{c}\text { Motor rotation } \\
\text { angle, } \varnothing\end{array}$} & \multicolumn{9}{|c|}{ Pipe bending angle, $\beta$} \\
\cline { 2 - 12 } & $0 \mathrm{~g}$ & $100 \mathrm{~g}$ & $200 \mathrm{~g}$ & $300 \mathrm{~g}$ & $400 \mathrm{~g}$ & $500 \mathrm{~g}$ & $600 \mathrm{~g}$ & $700 \mathrm{~g}$ & $800 \mathrm{~g}$ & $900 \mathrm{~g}$ & $1000 \mathrm{~g}$ \\
\hline 10 & 10.7 & 11.3 & 9.3 & 7.7 & 7.7 & 7.0 & 6.7 & 6.7 & 6.0 & 4.7 & 4.0 \\
\hline 20 & 20.3 & 20.7 & 17.7 & 17.3 & 15.7 & 13.7 & 10.7 & 10.7 & 9.7 & 8.7 & 8.3 \\
\hline 30 & 30.3 & 31.0 & 28.3 & 24.3 & 25.0 & 22.3 & 20.7 & 20.3 & 20.7 & 19.7 & 18.0 \\
\hline 40 & 39.3 & 35.7 & 36.0 & 33.7 & 34.3 & 31.7 & 31.7 & 31.3 & 30.0 & 29.0 & 0.0 \\
\hline 50 & 49.0 & 48.3 & 42.3 & 42.0 & 41.0 & 40.0 & 39.7 & 39.7 & 40.3 & 39.0 & Jerk \\
\hline 60 & 57.0 & 55.7 & 52.0 & 51.3 & 53.0 & 51.0 & 50.3 & 50.0 & 48.3 & Jerk & Jerk \\
\hline 70 & 66.7 & 64.7 & 58.7 & 57.3 & 56.7 & 55.3 & 54.3 & 53.7 & 54.0 & Jerk & Jerk \\
\hline 80 & 75.0 & 72.3 & 65.3 & 63.0 & 60.3 & 60.7 & 60.7 & 60.0 & Jerk & Jerk & Jerk \\
\hline 90 & 83.0 & 79.3 & 71.3 & 69.3 & 77.7 & 69.7 & 69.3 & Jerk & Jerk & Jerk & Jerk \\
\hline
\end{tabular}

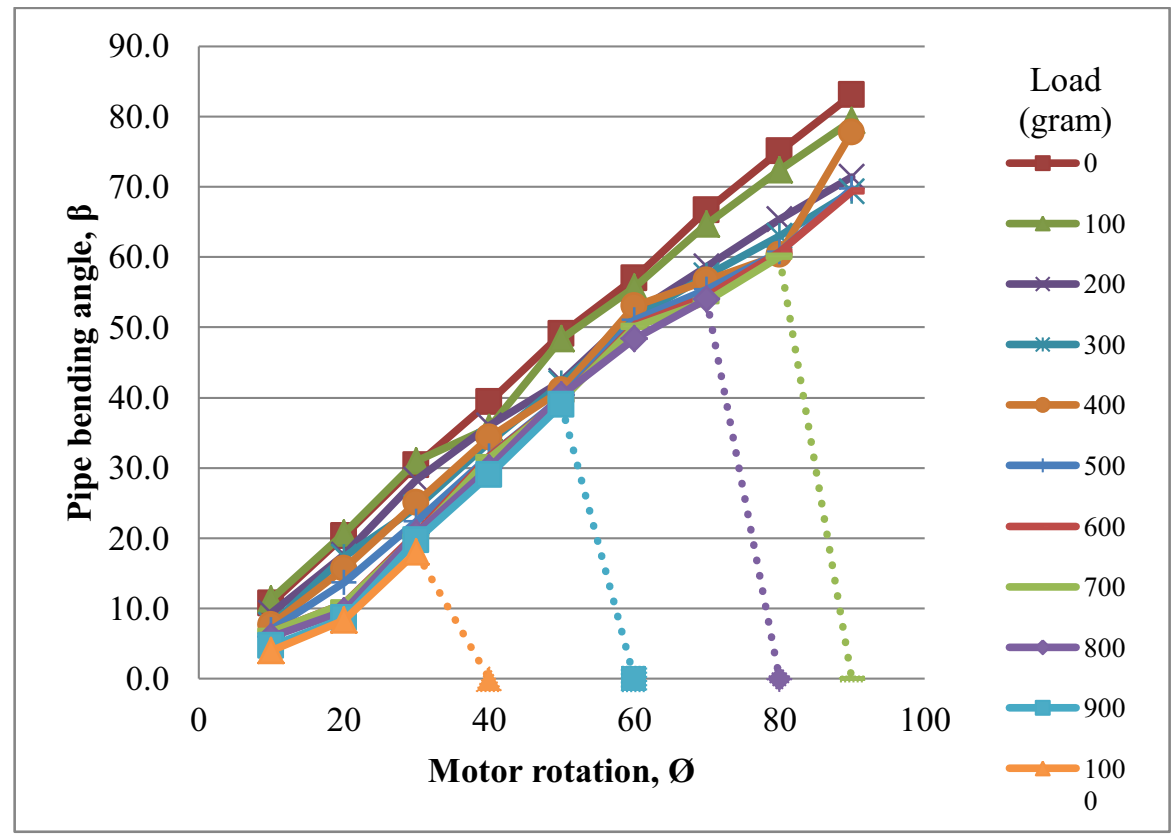

Fig. 6. Graph of servo motor rotational angle, $\varnothing$ versus vacuum hose bending angle, $\beta$. 
The main reason that the servo motor starts to jerk at a certain angle after implementing 600 gram of load was due to insufficient torque to overcome the gravitational force as well as the bending resistance stiffness of the hose. The specified servo motor holding torque is 1.7 N.m $(17 \mathrm{~kg} . \mathrm{cm})$, which signify that a combination of gravitational force and bending resistance (stiffness) is at equilibrium with the motor holding torque. From the graph in Figure 6 , the resulting bending angle for different motor rotation and different load can be estimated.

\section{Conclusion}

An additional one-degree-of-freedom has been introduced to the 4-DOF ABB FlexPicker robot by attaching a flexible vacuum hose as an alternative end effector. The end effector has the capacity to lift up to $1 \mathrm{~kg}$ of load in vertical motion, however, it can only lift up to $600 \mathrm{~g}$ with bending angle of 69.3 degrees. To increase the bending angle of the vacuum hose, the rotational angle of the servo motor can be increased by minor modification to the design of the end effector simply by removing the physical barrier that restricts the movement of the joint. Finally, further works are needed in order to increase the lifting capacity of the servo motor without sacrificing the weight ratio of the end effector with respect to the total maximum payload of the robot.

The experimental works were conducted at Robotic Laboratory, Faculty of Manufacturing Engineering, Universiti Teknikal Malaysia Melaka (UTeM) under grant no: PJP/2015/FKP(3C)/S01434.

\section{References}

1. M.Martin, K. Bernd, G. Harald, Conference ISR ROBOTIK,Munich, 225 (2014)

2. J. Brinker, B. Corves, The 14th IFToMM World Congress (2015)

3. K. Appu, Robotics. I.K. International Publishing House Pvt. Ltd., 13, (2007)

4. http://www.avs-yhtiot.fi/sites/default/files/pdf/7.01.05 alipaine_ohje.pdf

5. IRB 340 Industrial Robot Datasheet, ABB Automation Technologies (2005)

6. FESTO, Basic Principle of Vacuum Technology (2015)

7. BOSCH, Packaging Line Automation using Delta Robots (2015)

8. I. Bonev, Delta Parallel Robot - the Story of Success (2001)

9. H. Wu. (2010), Developing an Integrated System for Automating Picking and Sorting using an ABB FlexPicker Robot, Master's Thesis. Massey University (2010) 